\title{
PROPERTIES OF ARCTIC HAZE AEROSOL FROM LIDAR OBSERVATIONS DURING IAREA 2015 CAMPAIGN ON SPITSBERGEN
}

\author{
Iwona S. Stachlewska ${ }^{1}$, Christoph Ritter ${ }^{2}$, Christine Böckmann ${ }^{3}$, Ronny Engelmann ${ }^{4}$, \\ ${ }^{1}$ University of Warsaw, Faculty of Physics, Institute of Geophysics, IGFUW, Warsaw, Poland, \\ iwona.stachlewska@igf.fuw.edu.pl \\ ${ }^{2}$ Alfred-Wegener-Institute for Polar and Marine Research, AWI, Potsdam, Germany \\ ${ }^{3}$ University of Potsdam, Potsdam, Germany \\ ${ }^{4}$ Leibnitz Institute of Tropospheric Research, TROPOS, Leipzig, Germany
}

\begin{abstract}
Arctic Haze event was observed on 5-8 April 2015 using simultaneously Near-range Aerosol Raman Lidar of IGFUW and Koldewey Aerosol Raman Lidar of AWI, both based at AWIPEV GermanFrench station in Ny-Ålesund, Spitsbergen. The alterations in particle abundance and altitude of the aerosol load observed on following days of the event is analyzed. The daytime profiles of particle optical properties were obtained for both lidars, and then served as input for microphysical parameters inversion. The results indicate aerosol composition typical for the Arctic Haze. However, in some layers, a likely abundance of aqueous aerosol or black carbon originating in biomass burning over Siberia, changes measurably the Arctic Haze properties.
\end{abstract}

\section{INTRODUCTION}

During the transition form early spring to summer, the Arctic front expands over a large fraction of Northern Hemisphere and moves towards lower latitudes. This causes strong intrusions at different altitudes in the troposphere of polluted air-masses originating from industrial areas in Europe, Siberia, and/or North America. Due to the stable atmospheric conditions, low cloud cover, and low precipitation during late winter and early spring in the Arctic, this long-range transported aerosol can be trapped in the Arctic troposphere even for a month. The Arctic Haze particles are of a submicron size (Ångström exponent 1-1.5), well-aged (accumulation mode), with substantial fraction of sulfate (cooling effect) and soot (warming effect). Presence of absorbing particles in the troposphere causes a local warming at the altitude of their existence and, at the same time, a cooling below it at the ground. Measurements have shown that black carbon found in Arctic Haze events over Spitsbergen seem to be a minor but an important component, due to its absorbing properties [1]. In the frame of the iAREA Project (Impact of Absorbing aerosols on Radiative forcing in the European Arctic), a field campaign was performed from 26 March to 7 May 2015 at Ny-Ålesund. One of the aims of this campaign was at profiling of absorbing particles during haze season by using the iCAP comprising particle counter and microaethalometer installed under a tethered balloon. These in-situ data profiles were combined with ground-based observations of advanced Raman lidar and allowed to obtain a new methodology for absorption coefficient profiling [2]. Another aim, discussed in this paper, was at exploring solely the Raman lidar data for complex retrieval of optical and microphysical properties of Arctic Haze.

\section{INSTRUMENTS}

The Near-range Aerosol Raman lidar receiver (NARLa) [3], was developed to serve along with the advanced 8 -channel $(2 \alpha+3 \beta+2 \delta+\mathrm{WV})$ aerosoldepolarization-Raman lidar (ADR lidar) of the NeXT ganerationn Polly ${ }^{\mathrm{XT}}$-type [4] which is used for regular EARLINET measurements at IGFUW Radiative Transfer Laboratory (RTLab) in Warsaw. NARLa development was dedicated to improve Raman detection range within boundary layer at 4-channels $(2 \alpha+2 \beta)$. The NARLa is based on a Newtonian type telescope of a $5 \mathrm{~cm}$ diameter and a $20 \mathrm{~cm}$ focal length, which is combined with a fiber core of $0,4 \mathrm{~mm}$, resulting in $\mathrm{FOV}$ of $2 \mathrm{mrad}$. 
The elastic signals are detected at $355,532 \mathrm{~nm}$ and Nitrogen Raman channels at $387,607 \mathrm{~nm}$. For all channels signals are acquired in a photon counting mode with a low overall dead-time of about $2 \mathrm{~ns}$. The first 256 signal bins are allocated for a pretrigger. The signal is obtained up to $40 \mathrm{~km}$ with a $7.5 \mathrm{~m}$ spatial resolution. For experiment discussed in this paper, NARLa was installed next to Koldewey Aerosol Raman Lidar (KARL) [5] at the AWIPEV station in Ny-Ålesund from 27 March to 6 May 2015. The KARL's laser was used as a radiation source for NARLa. KARL is a coaxial Nd:Yag based system emitting IR, VIS, and UV pulses of $\sim 10 \mathrm{~W} /$ color (beam divergence is $0.6 \mathrm{mrad})$. Detection is done at 9-channels $(2 \alpha+3 \beta+2 \delta+2 \mathrm{WV})$ using a $70 \mathrm{~cm}$ diameter receiving mirror. An aperture stop is adjustable (position and diameter) and allows for measurements in the troposphere (overlap range $<700 \mathrm{~m}$ ) and stratosphere. KARL is member of the NOAA-NDACC network.

\section{METHODOLOGY}

Pre-selection of KARL and NARLa signals was done with a purpose to obtain a data set of particle optical properties, as appropriate for performing inversion of particle microphysical parameters at various layers. Selection was based on inspecting the range and background corrected signal plots at $532 \mathrm{~nm}$, then all signals were evaluated using the VerlaufNG5t.vi software approved for standard EARLINET retrieval [6]. The daytime profiles of aerosol extinction coefficient were obtained for both lidars using the classical Raman technique with Ansmann approach; then the particle backscatter coefficient profiles were calculated (Fig.1). All NARLa profiles were obtained with $7.5 \mathrm{~m} / 20 \mathrm{~min}$ resolution with the same smoothing applied prior to the optical retrieval. KARL data were evaluated with $30 \mathrm{~m} / 10 \mathrm{~min}$ resolution without smoothing. Calculations were done with use of RS92-Vaisala sonde launched everyday at 11/23UTC in Ny-Ålesund. From retrieved optical profiles, profiles of lidar backscatter-to-extinction ratio and Ångström exponent were obtained(Fig.1). The lidar derived aerosol optical depth was obtained by integrating the extinction profiles, interpolated with the extinction coefficient value derived at the completed overlap range height.
The microphysical retrieval algorithm is based on a concept of using the truncated singular value decomposition as a regularization method. This method was adapted to work for the retrieval of the particle size distribution (PSD) and is called the hybrid regularization technique $[8,9,10]$, since it uses a triple of regularization parameters to invert a mono-modal or bimodal PSDs. Inversion of an ill-posed problem (such as PDS retrieval) is a challenging task, as small measurement errors and tiny rounding errors often will be hugely amplified during the solution process, unless an appropriate regularization method with carefully determined regularization parameters is used. Therefore, we use two regularization techniques in parallel, for comparison purposes. The iterative regularization method is based on Páde iteration. Here, the well-known L-curve method serves as a regularization parameter choice rule. The approximated PSD is a linear combination of Bsplines with appropriately determined weights. The B-splines of order $d$ are polynomials of degree $d-1$. Since the distribution of the B-spline nodes also plays a critical role, we modified the first algorithm such that a non-equidistant node grid can be used. Later, the iterative method was equipped with an adaptive non-equidistant node grid. One more challenge was considered; as the complex refractive index (CRI) is actually also unknown, a grid of viable alternatives for the CRI (all combinations of real parts of CRI and imaginary parts of CRI) is assumed [7, 8, 9].

\section{RESULTS AND DISCUSSION}

Analysis of the NARLa and KARL data, obtained between 5-8 April 2015 at Ny-Ålesund shows enhanced aerosol loads with max. up to $3.5 \mathrm{~km}$, in comparison to e.g. 3 April when only background aerosol was observed [3]. During the event, the obtained mean particle backscatter coefficient values, calculated for a $100 \mathrm{~m}$ thick layer at an altitude corresponding to the max. aerosol load, were relatively low: $0.78-1.76 \mathrm{Mm}-1 \mathrm{sr}-1$ at $355 \mathrm{~nm}, 0.51-0.93 \mathrm{Mm}-1 \mathrm{sr}-1$ at $532 \mathrm{~nm}, 0.32-0.67$ $\mathrm{Mm}-1 \mathrm{sr}-1$ at $1064 \mathrm{~nm}$. However, aerosol optical depth (AOD) calculated from the ground to the upper age of aerosol layer, was high of 0.1-0.15 at $532 \mathrm{~nm}$ and of $0.13-0.19$ at $355 \mathrm{~nm}$. The Ångström exponent $(\mathrm{AE}>1.6)$ indicated small particles and 
lidar ratios (LR) of $58-82 \mathrm{sr}$ at $532 \mathrm{~nm}, 46-74 \mathrm{sr}$ at $355 \mathrm{~nm}$ indicated polluted arctic conditions. The color ratio of lidar ratios at 532/355 was changing gradually form 1.1 to 1.4 during the event. The linear particle depolarization ratios (KARL measurements; not shown, for brevity), were a background one or very small. These values confirm likeliness of the Arctic Haze occurrence.
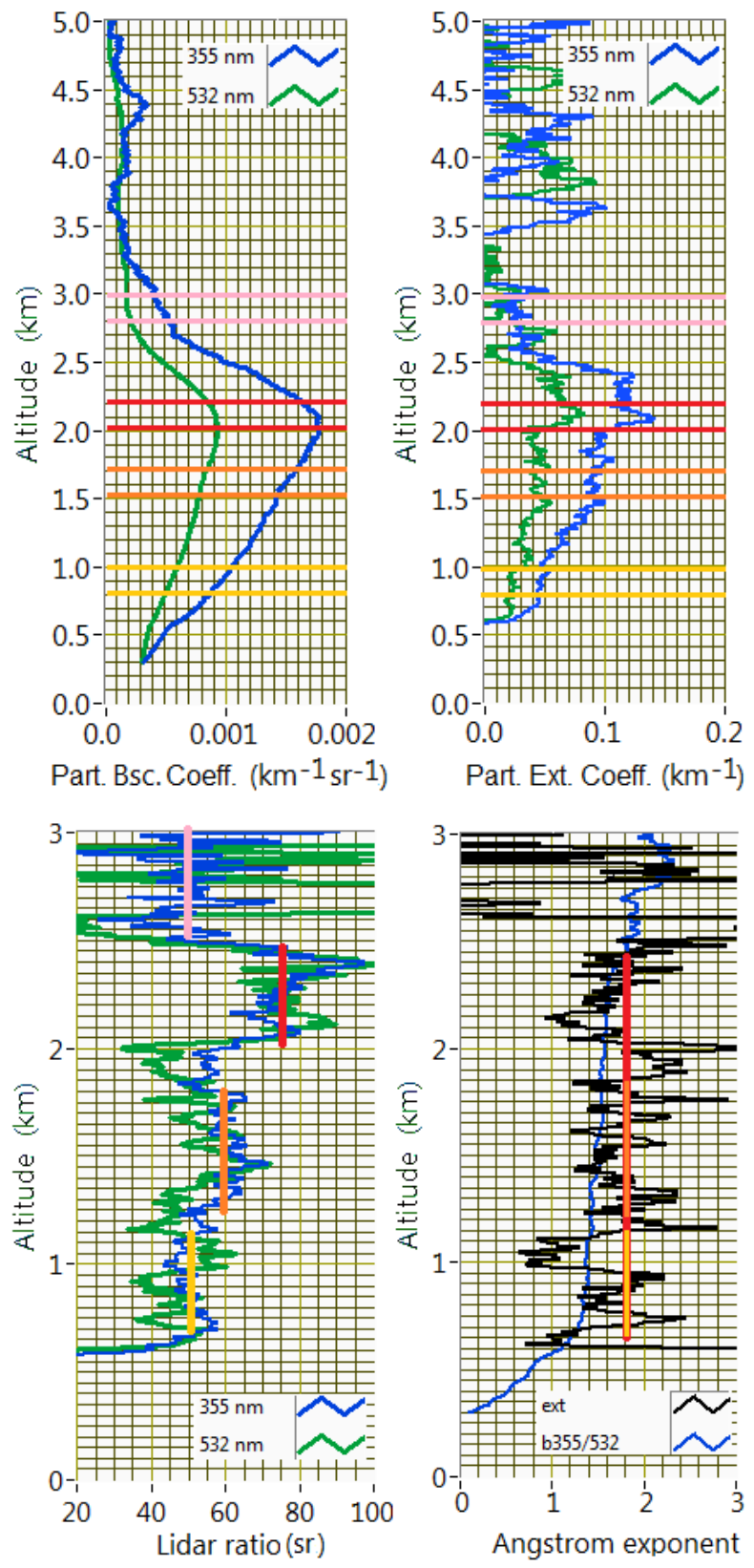

Figure 1 Profiles of optical properties retrieved from NARLa data at 22:40UTC on 6 April 2015.
The microphysical inversion was performed based on NARLa $2 \alpha+2 \beta$ at $355,532 \mathrm{~nm}$ supported with KARL $\beta$ at $1064 \mathrm{~nm}$. In general, results obtained for the entire event at different layers and different days show following features: A monomodal PSD with an accumulation mode of particles with an effective radius (Radii) of $407-501 \mathrm{~nm}$, the real part of complex refractive index (Re CRI) of 1.421.51 significantly higher than for water particles, and the imaginary part (Im CRI) of 0.007-0.015 indicating likely absorption. Particle concentration $N$ was in the range of $60-362 \mathrm{part} / \mathrm{cm} 3$. Single scattering albedo was very low (SSA $<0.92$ at $355 \mathrm{~nm}$ and $<0.94$ at $532 \mathrm{~nm}$ ), again in favor of absorbing particles.

A careful analysis of the inversion data (in temporal and vertical extent) indicate considerable changes in the aerosol composition during this event. For the highest aerosol abundance of the event, observed on April 6 (Fig.1, upper panels), at selected ranges (colored boxes) the optical properties are visibly different. Herein, we interpret differences that can be seen in the weakest aerosol load at an altitude of circa $2.8 \mathrm{~km}$ (pink) and in the strongest aerosol load at circa $2.3 \mathrm{~km}$ (red). Especially, we attempt to explain the origin of a high LR ( $\sim 75 \mathrm{sr}$, Fig.1, lower panels) obtained in the latter layer.

In free-troposphere, in uppermost layer at $2.8 \mathrm{~km}$, (Figs.1,2 in pink), the Re CRI of 1.51, Im CRI of 0.04 , monomodal PSD with Radii of $500 \mathrm{~nm}$ and $N$ of $60 \mathrm{part} / \mathrm{cm} 3$ was derived. This values can be interpreted along with the radiosounding data, as dry absorbing particles (Fig.3, RH $<65 \%$ ). For this layer, ensemble 10-days back-trajectories indicate likely biomass burning (black carbon) transport from over Siberia.

In the layer at $2.3 \mathrm{~km}$ (Figs. 1,2 in red), the $R e$ CRI of 1.48 and Im CRI of 0.03, with bi-modal PSD, which is dominated by particles with a fine mode Radii of $210 \mathrm{~nm}$ and very high $N$ of $501 \mathrm{part} / \mathrm{cm} 3$. In the second larger mode with Radii of $1130 \mathrm{~nm}$, a very low $\mathrm{N}$ of $0.46 \mathrm{part} / \mathrm{cm} 3$ was retrieved. These results indicate presence of only slightly less absorbing particles, which in this case were wet and accumulated above an inversion layer (Fig.3, RH $>85 \%$ ). 


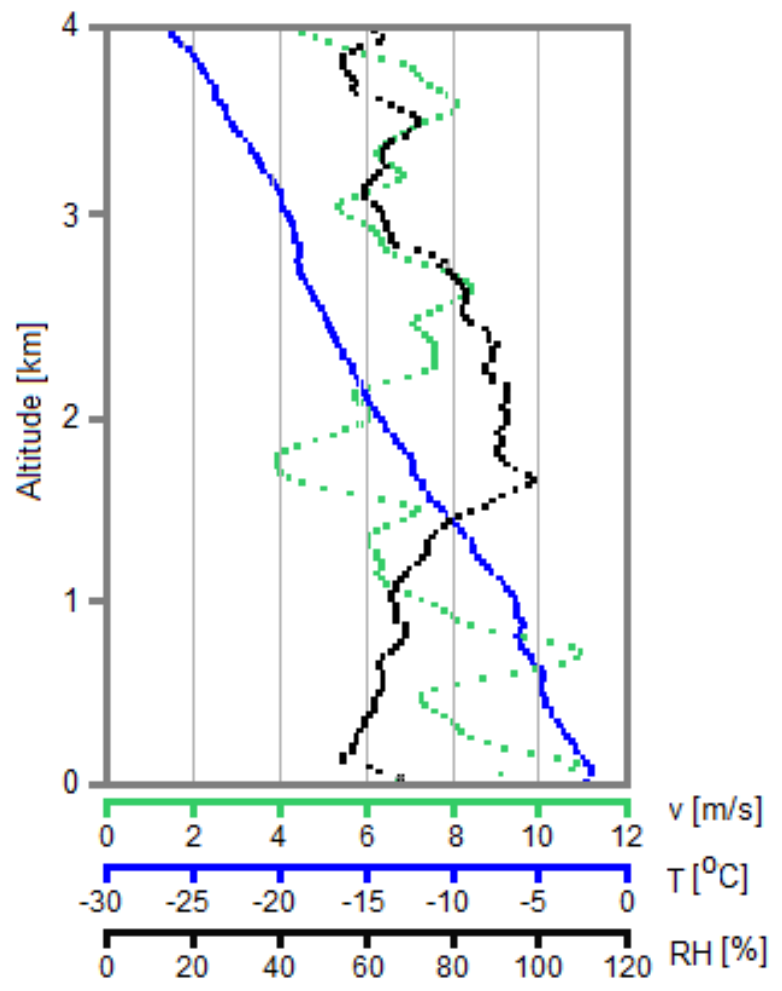

Figure 2 Termodynamical profiles obtained by radiosonding in Ny-Allesund 23UTC on 6 April 2015.

\section{CONCLUSIONS}

A characteristics of the optical and microphysical particle properties during the Arctic Haze event of 5-8 April 2015, in Ny-Ålesund, Spitzbergen was obtained and discussed. Evidence for existence of a humid layer and its influence on the properties of Arctic Haze is given. This results complement studies of humid layers, as characterized by extremely high lidar ratios, that are occurring regardless of polluted or background Arctic conditions and were reported during several airborne campaigns of AWI [e.g. 10].

\section{ACKNOWLEDGEMENTS}

The NARLa was developed in collaboration of IGFUW and TROPOS in the frame of SONATA-BIS Project: Integrated study of climate processes involving absorbing aerosols funded by National Science Centre of Poland (2012/05/E/ST10/01578).

The iAREA campaign was financed within the project: Impact of absorbing aerosols on radiative forcing in the European Arctic funded by Polish-Norwegian Research Programme (Pol-Nor/196911/38/2013).
This research work was partly supported by the EUFP7 for research, technological development and demonstration (Grant No.289923 ItaRS), and the EU's Horizon 2020 research and innovation programme (Grant No. 654109 ACTRIS-2).

\section{References}

[1] Yamanouchi T., et al. 2005: Arctic Study of Tropospheric Aerosol and Radiation (ASTAR) 2000: Arctic haze case study, Tellus 57B, 141-152

[2] Markowicz, K.M, C. Ritter, J. Lisok, P. Makuch, I.S. Stachlewska, D. Cappelletti, M. Mazzola, M.T. Chilinski, 2017: Vertical variability of aerosol singlescattering albedo and black carbon concentration based on in-situ and remote sensing techniques during iAREA campaigns in Ny-Ålesund, Atmos. Environ., vol. 164, pp. 431-447, 10.1016/j.atmosenv.2017.06.014

[3] Stachlewska I.S., et al. 2016: Near-range receiver unit of NeXT generation PollyXT used with Koldeway Aerosol Raman Lidar in Arctic, ILRC27, New York

[4] Engelmann R., et al. 2016: The automated multiwavelength Raman polarization and water-vapor lidar PollyXT: the neXT generation, Atmos. Meas. Tech. 9, 1767-1784

[5] Ritter C., Neuber R., Schulz A., Markowicz K.M., Stachlewska I.S., Lisok J., Makuch P., Pakszys P., Markuszewski P., Rozwadowska A., Petelski T., Zielinski T., Becaglie S., Traversie R., Udistie R., Gausaf M., 2016: 2014 iAREA campaign on aerosol in Spitsbergen - Part 2: Optical properties from Ramanlidar and in-situ observations at Ny-Ålesund, Atmos. Environ. Vol.141 1-19 10.1016/j.atmosenv.2016.05.053

[6] Baars H., et al. 2016: An overview of the first decade of PollyNET: an emerging network of automated Raman-polarization lidars for continuous aerosol profiling, Atmos. Chem. Phys., 16, 5111-5137.

[7] Böckmann C., et al. 2017: Arctic biomass burning aerosol event microphysical property retrieval, ILRC28, Bucharest, (this issue).

[8] Müller D., et al. 2016: Microphysical particle properties derived from inversion algorithms developed in EARLINET, Atmos. Meas. Tech. 9, 5007-5035.

[9] Samaras S., et al. 2015: Using Raman-lidar-based regularized microphysical retrievals and aerosol mass spectrometer for characterization of biomass burning aerosols, J.Comput.Phys. 299,156-174.

[10] Stachlewska I.S. and Ritter C. 2010: On retrieval of lidar extinction profiles using Two-Stream and Raman techniques, Atmos.Chem.Phys., 10, 2813-2824 